\title{
Awareness of diabetic foot disease amongst patients with type 2 diabetes mellitus attending the chronic outpatients department at a regional hospital in Durban, South Africa
}

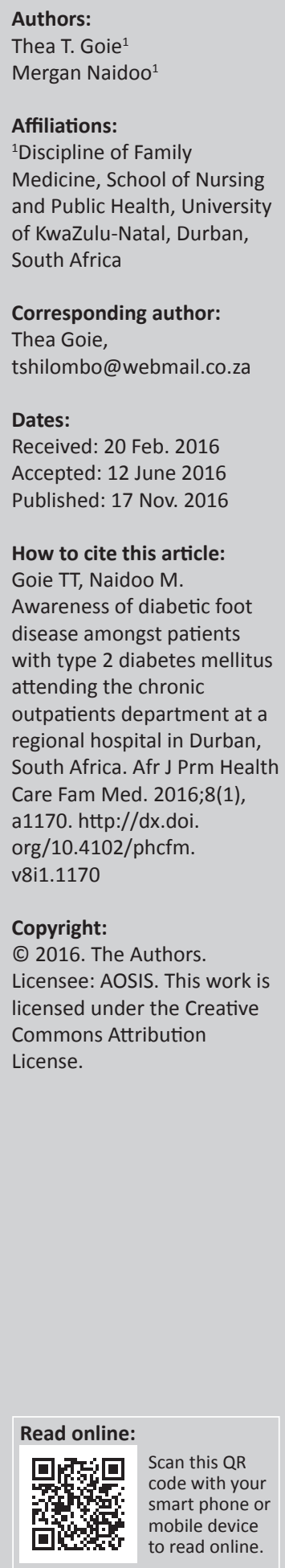

Background: Diabetic foot disease (DFD) is a major challenge for the healthcare system, with enormous economic consequences for people living with diabetes, their families, and society, affecting both quality of life and quality of care. The study aim was to assess the level of awareness of DFD amongst patients with type 2 diabetes mellitus (T2DM).

Methods: An observational descriptive cross-sectional study was conducted at the chronic outpatients department of a regional hospital in Durban, South Africa.

Results: Two hundred participants with T2DM participated in the study. Ninety-one per cent of participants were either overweight or obese. Ninety-two per cent of participants had concomitant hypertension (57.5\%), dyslipidaemia (26.7\%) and eye disease (7.2\%). Seventy-six per cent reported altered sensation in their lower limbs, and $90 \%$ reported having no previous DFD education. Only $22.2 \%$ of participants reported having examined their feet, but only when they experienced a problem. Participants achieved mediocre scores for knowledge (mean 4.45, standard deviation (s.d.) 2.201, confidence interval (CI) 4.2-4.7) and practice (mean 11.09, s.d. 2.233, CI 10.8-11.5) on diabetic foot care (DFC). Those who had a higher level of education and who were less than 65 years old had a significantly better score for previous foot care education $(p<0.05)$.

Conclusion: The study demonstrated that awareness of DFD was suboptimal, based on current DFC guidelines. To minimise the burden of DFD, improved screening and prevention programmes as well as patient education should be provided to T2DM patients, whilst maintaining an aggressive approach to risk factor modifications, footwear and identifying the at-risk foot.

\section{Introduction}

More than 350 million people worldwide were known to have diabetes mellitus (DM) in 2013, and an estimated 592 million are expected to have the disease by 2035. Most of these people are between 40 and 59 years of age, and live in low- and middle-income countries (LMICs) ${ }^{1,2}$ It is also estimated that $50 \%$ of people with DM are undiagnosed. The World Health Organization (WHO) estimates that DM will be the seventh leading cause of death in the next 15 years. ${ }^{1}$

The five sub-Saharan African countries with the highest rate of type 2 DM (T2DM) are Nigeria, South Africa, Ethiopia, the Congo and Tanzania. ${ }^{2,3}$ Owing to the 'westernisation' of rural African communities, the prevalence rate of DM has increased amongst persons of indigenous descent. ${ }^{3,4}$ In South Africa (SA), the prevalence of DM amongst the black population is second only to the prevalence of South Africans of Indian descent. ${ }^{5}$

One of the most common and distressing complications that affects diabetic patients is diabetic foot disease (DFD). ${ }^{6,7}$ DFD comprises a constellation of vascular and neurological pathologic changes that are the direct result of DM, causing local tissue destruction by sensory neuropathy and compromise of the vascular system of the affected lower extremities in diabetic sufferers. ${ }^{1,8}$ These contributory factors co-exist in more than $10 \%$ of patients at the time of diagnosis of T2DM. ${ }^{78}$ DFD is a major challenge for the healthcare system in both high-income countries and LMICs, with substantial economic consequences for the patients, their families, and society. ${ }^{6,7}$ DFD accounts for $20 \%$ of all hospitalisations of T2DM patients in sub-Saharan Africa, and frequently leads to chronic disabilities, loss of income, lower limb amputation or death..$^{7,10,11}$ It is estimated that one in every five persons with DM (type 1 and type 2) has a 15\% probability of 
developing a foot infection in a year, and 5\% of DM patients with DFD will eventually undergo amputation..$^{12,13,14}$ Despite various interventions, DFD remains a common and significant clinical problem affecting quality of life and quality of care that disrupts patients' psychosocial and physical state and has a negative impact on their overall perception of the disease. ${ }^{15,16,17}$ DFD leads to physical limitation and functional disability. ${ }^{15,16,17,18}$

Considering that the patient is the primary foot carer, it is essential that to reduce the incidence of foot disease amongst patients with T2DM, they have a good awareness of the risk factors that could predispose or worsen DFD, as well as awareness of good foot care practice. . $9,13,19,20,21^{\text {Commonly, }}$ DFD develops in areas of the foot exposed to continuous pressure, friction and repetitive trauma. Harmful footwear such as those with unergonomic interiors, high heels and narrow foreparts, is one of the major precipitating causes implicated in the progression to DFD and amputation. Inappropriate shoes are sometimes considered 'enemies of the oppressed foot'. ${ }^{22,23}$ Evidence shows that knowledge is associated with better attitudes and practices of foot care, and should consequently bring clinical benefit - although this is not always the case, as the quality of care offered at primary healthcare (PHC) level in our settings is often unsatisfactory. ${ }^{24,25}$ More studies need to be performed to evaluate whether clinical benefit may arise from educationtargeted community programmes in comparison with the usual care provided. ${ }^{25}$ Awareness of good foot care is essential amongst T2DM patients and health care providers to reduce the incidence of foot disease, and this would involve:

- preventing and managing local trauma and/or infection

- dealing with foot deformities

- managing abnormal pressure points

- improving poor glycaemic control

- managing pre-existing vascular damage and/or peripheral neuropathy

- managing associated cardiovascular diseases

- improving awareness and self-practice of foot care..$^{25,26}$

Awareness involves the ability to know and understand those factors that will further develop beliefs, and dictates attitudes and practices toward responsibility, improvement and success. The aim of the present study was to assess the level of awareness of DFD amongst patients with T2DM who attend the chronic outpatients department (OPD) at a regional hospital in Durban, SA. The specific objectives included briefly assessing the clinical profile of T2DM patients and evaluating their knowledge, attitudes and practices concerning DFD.

\section{Methods}

The study was an observational descriptive cross-sectional study that was conducted at a regional hospital in the city of Durban in KwaZulu-Natal, SA, during October 2014.
The hospital is a 1200-bed institution that serves a large catchment area consisting of urban and rural populations. It provides district and regional levels of care to patients, with an average of 43000 patients visiting OPD monthly.

The hospital's OPD for chronic patients is run by the Department of Family Medicine, and diabetic clinics are on Mondays, Thursdays and Fridays. The chronic OPD provides ambulatory care to approximately 700 diabetic patients monthly. A sample size of 280 which represents approximately $36 \%$ of the monthly patient load was considered appropriate for the study, after consultation with the biostatistician. The inclusion criteria were T2DM patients who were $\geq 18$ years, had been on treatment for $\geq 12$ months, and attended the diabetic clinic at the chronic OPD at this hospital.

Patients who did not consent to participate in the study, those who were cognitively impaired and those who had debilitating mental illnesses were excluded from the study. A systematic randomised sampling method was used to select participants. Every third patient meeting the inclusion criteria was asked to participate in the study. Measures were in place to ensure that participants did not participate in the study more than once.

Validated questionnaires used to assess DFC in previous studies were adapted for the present study. ${ }^{27,28,29,30,31}$ The adapted questionnaire consisted of options with sections that covered socio-demographic and clinical profiles of patients, and knowledge, attitudes and practice variables. A pilot study of 10 patients allowed the modified questionnaire to be used. The questionnaire was translated into the local language isiZulu for patients who could not speak/read English, and back-translated into English to ensure accurate translation. A research assistant who was proficient in isiZulu was trained and worked with the principal investigator throughout the process of data collection. Signed written informed consent was obtained from each participant. The questionnaire and an information sheet were distributed by hand to each participant. All questionnaires were filled out anonymously to protect confidentiality of participants. Minimal information was collected from participants' medical records. Ethics approval to conduct the study was granted by the Biomedical Research Ethics Committee (BREC) of the University of KwaZulu-Natal (reference number 290/14) and the provincial Department of Health. Data were captured on an Excel spreadsheet and analysed using IBM SPSS version 23 by the biostatistician. Linear correlation (Pearson coefficient), $p$ values and confidence intervals were calculated to ascertain the statistical significance of any correlation found. The level of significance was set at $p<0.05$.

\section{Results}

Two hundred and ninety-nine participants gave informed consent and received the questionnaire. Nineteen participants 
dropped out whilst filling in their answers, some saying that they had to rush elsewhere, and others for no particular reasons. A total of 280 participants with T2DM participated in the study, of whom $201(71.8 \%)$ were female and $79(28.2 \%)$ were male. Their mean age was $59 \pm 9.28$ years. Most participants were black (89.6\%). There were 27 (9.6\%) Indian participants, one white participant and one of coloured origin $(0.4 \%$ each). One hundred and sixty participants were married. Ten participants (3.6\%) had tertiary education, of whom $60 \%$ were female. Fifty-four $(68 \%)$ of the male subjects had no formal education. Almost $59 \%$ of participants $(n=164)$ received between R1000 and R1999 monthly, comprising government social grants, and $29 \%$ of participants $(n=81)$ earned $<$ R500. Ninety-one per cent of participants were either overweight or obese (Figure 1).

Eighty-four (30\%) participants had been diagnosed with T2DM in the past 5 years, and $21.4 \%$ of participants possessed a glucometer. Most (95\%) participants only visited the diabetic clinic for their treatment, and $91.8 \%$ visited the clinic monthly. Ninety-five per cent of participants had concomitant existing medical conditions. The three most common comorbidities were hypertension $(57.5 \%)$, dyslipidaemia (26.7\%) and eye disease (7.2\%). Concomitant peripheral neuropathy was found in 3\% of participants. All participants were on medication for T2DM, with 12 participants stating that they were not taking their medication regularly $(n=5)$ or had defaulted on their treatment $(n=7)$. Seventy per cent of participants practised one or more forms of exercise, of whom $65.7 \%(n=130)$ exercised for 30 minutes a day or 150 minutes per week. Others $(13 \% ; n=27)$ exercised $<30$ minutes per day or had an irregular exercise schedule ( $n=26)$. The most practised form of exercise was walking $(49.8 \%)$, followed by gardening (36.3\%) and jogging $(8.50 \%)$. Eighty-seven per cent of participants claimed to be on a lowfat no-sugar diet, with $66.8 \%$ observing this diet sometimes and $33.2 \%$ claiming to be always compliant with this dietary regime. Ninety-seven $(34.6 \%)$ patients monitored their body weight regularly.

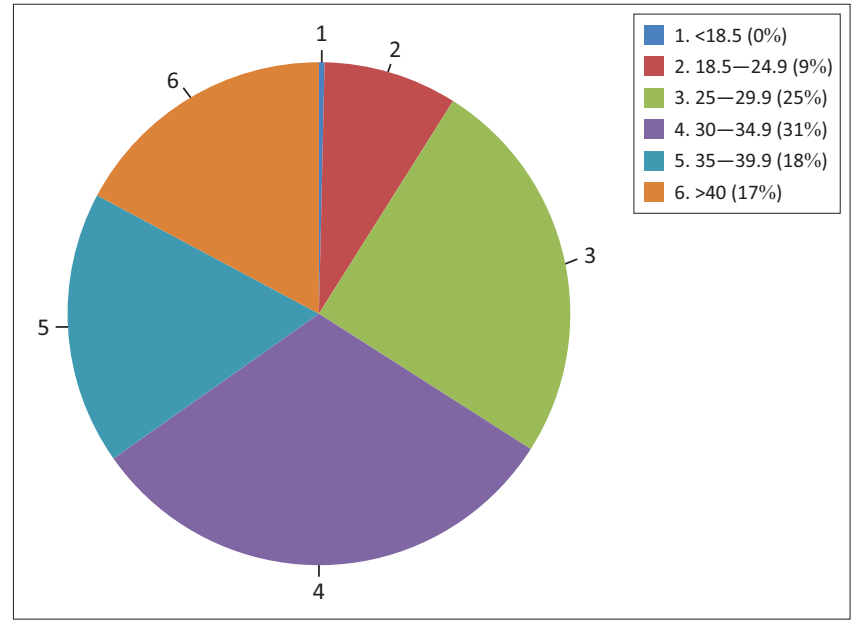

Source: Questionnaire; http://reference.medscape.com/calculator/body-mass-index-bm FIGURE 1: Body mass index frequencies.
Table 1 represents the distribution of patients regarding previous and current DFD. Some patients had one or more types of DFD.

Most (76\%) participants reported having altered sensation (i.e. tightness and numbness) in their lower limbs at the time of the interview. These participants were mostly aged between 50 and 64 years (55.6\%) with an additional 13\% between the ages of 35 and 49 years who also reported having these symptoms (Figure 2). Seventy-one per cent of participants with altered sensation were diagnosed with T2DM for 5 years and more.

Table 2 presents the level of knowledge and attitudes of DFC and previous diabetic foot education. Table 3 presents the level of practice of DFC.

Most patients believed that DM would eventually lead to DFD, that smoking contributes to reduced blood flow to the limbs, and that dietary measures are important in controlling DM. They also believed that they could live a normal life notwithstanding T2DM. Most participants said that foot examination should be their own responsibility. More than $90 \%$ of participants had not received any previous form of DFC education from any source.

Sixty-five per cent of participants examined their feet every day, and 22.2\% examined their feet only when they had a problem. Ninety-four per cent of participants who did not cut their own toenails had it done by a family member. Of the 265 participants who trimmed their toenails, $79.3 \%$ trimmed their nails along the edges and $20.7 \%$ trimmed them straight. Participants wore more than one type of shoe, with sandals

TABLE 1: Number of participants with previous and current diabetic foot disease.

\begin{tabular}{lrc} 
& \multicolumn{2}{c}{ Yes } \\
\cline { 2 - 3 } Symptoms & $\boldsymbol{n}$ & $\%$ \\
\hline Previous ulcer on feet & 26 & 9.3 \\
Previous amputation & 11 & 4.0 \\
Current ulcer on feet & 10 & 3.6 \\
Current blood/discharge on feet & 6 & 2.1 \\
Current calluses & 37 & 13.2 \\
Current numbness and tightness in lower limbs & 214 & 76.4 \\
\hline
\end{tabular}

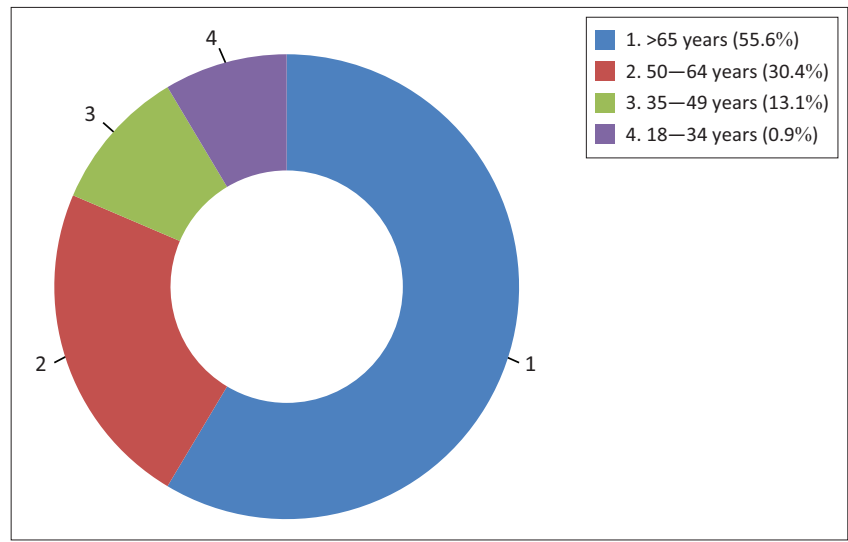

FIGURE 2: Distribution of participants with current numbness and tightness in lower limbs per age ranges. 
TABLE 2: Knowledge and attitudes about diabetic foot care and previous diabetic foot education.

\begin{tabular}{|c|c|c|c|c|}
\hline \multirow[b]{2}{*}{ Knowledge and attitudes } & \multicolumn{2}{|c|}{ Yes } & \multicolumn{2}{|c|}{ No } \\
\hline & $n$ & $\%$ & $n$ & $\%$ \\
\hline DM patients may develop reduced blood flow in their feet. & 147 & 52.5 & 133 & 47.5 \\
\hline DM patients may develop lack of sensation in their feet. & 180 & 64.3 & 100 & 35.7 \\
\hline DM patients may develop foot ulcers. & 167 & 59.6 & 113 & 40.4 \\
\hline DM patients may develop gangrene. & 204 & 72.9 & 76 & 27.1 \\
\hline Are you aware that smoking can reduce blood flow in your feet? & 175 & 62.5 & 105 & 37.5 \\
\hline Do you know that with loss of sensation in your foot, you are more prone to foot ulcers? & 107 & 38.2 & 173 & 61.8 \\
\hline Do you know that with reduced blood flow in your foot, you are more prone to foot ulcers? & 109 & 38.9 & 171 & 61.1 \\
\hline Do you know that if you have foot infection, you will develop foot ulcers? & 160 & 57.1 & 120 & 42.9 \\
\hline DM patients should take responsibility for self-foot examination. & 234 & 83.6 & 46 & 16.4 \\
\hline You can lead a normal life if you take appropriate measures to control your DM. & 248 & 88.6 & 32 & 11.4 \\
\hline Diet is important in the control of DM. & 265 & 95 & 14 & 5 \\
\hline Have you ever attended a class on how to care for your feet? & 3 & 1.1 & 277 & 98.9 \\
\hline Have you ever received education about foot care from the nurse? & 11 & 3.9 & 269 & 96.1 \\
\hline Have you ever received information about foot care whilst waiting to see the doctor? & 10 & 3.6 & 270 & 96.4 \\
\hline Have you ever read any hand-outs on foot care/foot wear? & 37 & 13.2 & 243 & 86.8 \\
\hline Would you like a hand-out on how to care for your feet? & 268 & 95.7 & 12 & 4.3 \\
\hline
\end{tabular}

DM, diabetes mellitus.

TABLE 3: Practice of diabetic foot care.

\section{Practice questions}

Can you reach your feet?

Do you examine your feet?

Do you wash your feet every day?

Do you dry between your toes?

Do you use cream on your feet?

Do you use cream between your toes?

Do you use medicated foot products?

Do you file your toenails?

Do you trim your toenails?

Do you walk barefoot?

Do you inspect your shoes prior to wearing them?

Do you soak your feet?

If Yes above, do you check the water temperature before soaking your feet?

Do you use a hot-water bottle on your feet?

Do you sit with your legs crossed?

Do you smoke?

\begin{tabular}{|c|c|c|c|}
\hline \multicolumn{2}{|c|}{ Yes } & \multicolumn{2}{|c|}{ No } \\
\hline$n$ & $\%$ & $n$ & $\%$ \\
\hline 193 & 68.9 & 87 & 31.1 \\
\hline 150 & 65.2 & 130 & 34.8 \\
\hline 277 & 98.9 & 3 & 1.1 \\
\hline 260 & 92.9 & 20 & 7.1 \\
\hline 98 & 35.0 & 182 & 65.0 \\
\hline 84 & 30.0 & 196 & 70.0 \\
\hline 28 & 10.0 & 252 & 90.0 \\
\hline 200 & 71.4 & 80 & 28.6 \\
\hline 265 & 94.6 & 15 & 5.4 \\
\hline 132 & 47.1 & 148 & 52.9 \\
\hline 245 & 87.5 & 35 & 12.5 \\
\hline 158 & 56.4 & 122 & 43.6 \\
\hline 139 & 88.0 & 19 & 12.0 \\
\hline 31 & 11.1 & 249 & 88.9 \\
\hline 93 & 33.2 & 187 & 66.8 \\
\hline 26 & 9.3 & 254 & 90.7 \\
\hline
\end{tabular}

and flip-flops being used by $83.2 \%$ of participants. Approximately $88 \%$ of participants wore socks regularly.

Table 4 shows descriptive statistics of knowledge, attitudes, practices and previous foot education scores.

Knowledge scores ranged from $0-8$, attitude scores from $0-3$, practice scores from $0-19$, and previous foot education from $0-7$. High scores represent best responses. The average attitude score was 2.67 with a low s.d. Previous foot education scores had the lowest mean.

Most participants with altered sensation in their lower limbs had not received previous DFD education and they had mediocre scores and average scores for knowledge and practice of DFC respectively (Figure 3).

The scores for participants with no altered sensation in their lower limbs $(23.6 \%, n=66)$ were significantly the same.
TABLE 4: Descriptive statistics of knowledge score, attitude score, practice score and previous foot education score.

\begin{tabular}{lcrcc}
\hline Scores & $\boldsymbol{N}$ & Mean & s.d. & Cl \\
\hline Knowledge score & 280 & 4.45 & 2.201 & $4.2-4.7$ \\
Attitude score & 280 & 2.67 & 0.556 & $2.6-2.7$ \\
Practice score & 280 & 11.09 & 2.233 & $10.8-11.5$ \\
Previous foot education score & 280 & 0.63 & 1.203 & $0.5-0.8$ \\
\hline
\end{tabular}

s.d., standard deviation; $\mathrm{Cl}, 95 \%$ confidence interval; $N$, number.

Table 5 presents the levels of significance of demographic variables and clinical profiles of participants compared with knowledge, attitude, practice and previous foot education regarding DFC.

There was a positive relationship between gender and attitude, with a positive Pearson coefficient $(r)$ of 0.168 and a $p$-value that was significant $(p<0.05)$. Men had a significantly higher attitude score than that of women. There was also a positive relationship between education level and previous foot care education $(p<0.05)$, with patients having a higher 
TABLE 5: Impact of demographic factors and clinical profile on patients' knowledge and practice of diabetic foot care.

\begin{tabular}{|c|c|c|c|c|c|c|c|c|}
\hline \multirow[b]{2}{*}{ Variable } & \multicolumn{2}{|c|}{ Knowledge } & \multicolumn{2}{|c|}{ Attitude } & \multicolumn{2}{|c|}{ Practice } & \multicolumn{2}{|c|}{ Previous foot care education } \\
\hline & $r$ & $p$ & $r$ & $p$ & $r$ & $p$ & $r$ & $p$ \\
\hline Gender & 0.070 & 0.123 & 0.168 & 0.002 & 0.062 & 0.152 & 0.069 & 0.126 \\
\hline 18-34 years old & 0.060 & 0.159 & 0.051 & 0.199 & 0.092 & 0.063 & 0.062 & 0.151 \\
\hline $35-49$ years old & 0.047 & 0.216 & 0.097 & 0.052 & 0.065 & 0.138 & 0.068 & 0.128 \\
\hline 50-64 years old & -0.002 & 0.486 & -0.054 & 0.183 & -0.018 & 0.384 & 0.039 & 0.258 \\
\hline$>65$ years old & -0.045 & 0.226 & -0.025 & 0.339 & -0.048 & 0.212 & -0.106 & 0.038 \\
\hline Education & -0.090 & 0.067 & 0.024 & 0.347 & 0.065 & 0.140 & 0.171 & 0.002 \\
\hline DM for $<5$ years & -0.090 & 0.660 & 0.072 & 0.116 & -0.310 & 0.304 & -0.068 & 0.128 \\
\hline DM for $\geq 5$ years & 0.093 & 0.610 & 0.077 & 0.101 & 0.270 & 0.326 & 0.077 & 0.098 \\
\hline
\end{tabular}

$r$, Pearson coefficient; $p$, $p$-value; DM, diabetes mellitus.

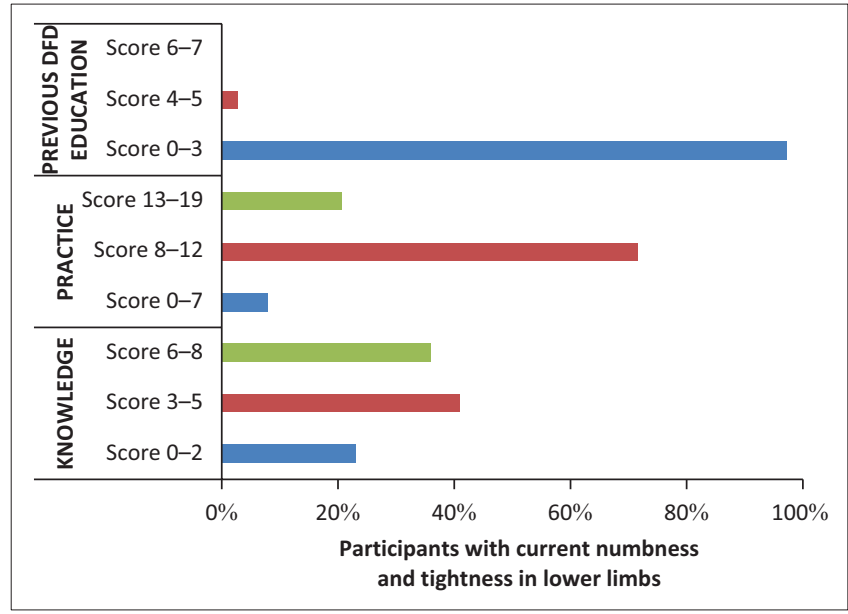

FIGURE 3: Scores for knowledge, practice and previous education on DFD, for participants with current numbness and tightness in lower limbs.

level of education achieving a better score. There was a significant negative correlation between participants aged $<65$ and the score for previous foot care education $(p<0.05)$, implying that people $<65$ are more likely to report a higher score for previous foot care education than people $\geq 65$.

\section{Discussion}

Despite the systematic randomised sampling method used, the genders were not equally represented, with 201 female v. 79 male participants in the study. Although the prevalence of T2DM is unequal amongst the genders worldwide, with more men having T2DM than women, studies have shown that there are more women with T2DM in SA and that more women attend outpatient clinics than do men. ${ }^{2,32,33,34,35}$ The mean age of 59 years is consistent with global figures of people with $\mathrm{DM}^{2}$

A large percentage of participants had a high body mass index (BMI), with a mean BMI of 33.4. This is a concern as obesity is a major risk factor for DM complications. Despite $87 \%$ of participants claiming to be on a diabetic diet, only $29 \%$ claimed to be on a low-fat no-sugar regime. A large percentage of participants acknowledged that diet was important in the control of their DM but only a minority of participants monitored their weight, which is consistent with studies elsewhere. ${ }^{36}$ Results of a recent BMI study and related mortality of patients with T2DM have indicated a J-shaped relationship between the two concepts, with an exponential increase in mortality demonstrated amongst T2DM patients who have higher BMIs. ${ }^{36}$

There is strong evidence that lifestyle modifications such as all types of physical activity, losing weight, ceasing smoking and following nutritional recommendations provide benefits in the prevention of hypertension, dyslipidaemia, diabetes and other cardiovascular diseases associated with T2DM, and can reduce DM itself. ${ }^{37,38}$ Of concern in our study is that the majority of participants were already affected by cardiovascular diseases. It was encouraging, however, that only $9 \%$ of participants smoked cigarettes, which may be related to the participants' racial composition. A study in South Africa that analysed the correlation between race and smoking status amongst adult South Africans concluded that smoking habits may be related to race. ${ }^{39}$ In SA, black people have the lowest smoking prevalence, and this prevalence is decreasing. ${ }^{40,41}$ Given that blacks represent about $75 \%$ of the total population in SA and almost $90 \%$ of our sample size, this finding may explain the relatively low smoking rates found in the present study. In DM, smoking accounts for more than half of the risks contributing to the development of peripheral artery disease and DFD. ${ }^{42,43,44}$ Participants had a fair level of awareness about the effect of smoking on the reduction of blood flow to the lower limbs. Generally, knowledge influences behaviour, which may be one of the reasons why a large proportion of participants were non-smokers. ${ }^{45,46}$ Improving knowledge by using smoking cessation interventions amongst T2DM patients may be a good public health strategy in decreasing the risks of DFD. ${ }^{40,41,47}$

Although the knowledge score had a high mean, there was great variance demonstrated by the high standard deviation. Participants had poor knowledge of the most significant factors for all types of DFD, namely the presence of foot infection/ulcer, peripheral neuropathy and peripheral vascular disease, which was consistent with other international studies. ${ }^{44,48}$ However, these results represent a slight improvement over previous findings of a South African study in which diabetic patients of black descent had poor knowledge of self-management of their disease. ${ }^{4,49}$ In our study, those at high risk for foot disease had overall average knowledge scores as well as foot care practices, as shown in Figure 3. Poor knowledge may be related to lack of provision of diabetic foot care education 
as well as the short period from the time that the diagnosis of DM was made, but this correlation was not demonstrated in the present study. ${ }^{50,51} \mathrm{~A}$ large retrospective cohort study emphasised the importance of screening for symptoms of foot disease in order to implement measures for the secondary prevention of DFD. All diabetic patients should be thoroughly screened for foot disease to identify at-risk feet. ${ }^{44,48}$ Confirmed peripheral neuropathy was found in only $3 \%$ of participants. Screening questions revealed that the majority of respondents had numbness and tightness in their lower limbs, a major symptom leading to DFD which requires that stringent management of associated risk factors be implemented to prevent progression of the disease. ${ }^{52}$ Ongoing integrated motivation and education leading to behaviour change should be given to diabetic patients at the first onset of symptoms of foot disease, as the risk of developing DFD is significantly high. ${ }^{52}$ Regular screening of T2DM patients for sensory and vascular foot changes and patient education programmes on DFD including advice on preventative actions, should be highlighted and reinforced in health institutions. . $^{11,44,48,51,53,54}$ Daily foot inspection by patients can prevent DFD and its fatal complications. The importance of good knowledge and practice should be stressed and reinforced in T2DM patients who have established peripheral neuropathy so as to reduce the number of diabetic amputations and improve survival. Those with positive features on a screening tool should have much tighter glycaemic control and be subject to more intensive foot care education programmes, with regular scheduled follow-up visits. ${ }^{7,51}$ Podiatrist services should be widely available at PHC level. ${ }^{55,56}$

In our study, foot care practice was poor, with a large variance. To avoid trauma to their lower limbs, T2DM patients with poor vision should let another party examine their feet, and their toenails should be trimmed using the correct technique, which is straight across..$^{52}$ Footwear usage was inappropriate, as many claimed to wear open footwear which would make them more prone to trauma and infection. 22,23,51,52 Studies have shown that there are reduced rates of DFD in patients when several intervention programmes, including footwear, are implemented. ${ }^{22,51}$ Counselling on the use of appropriate footwear is easy to implement in clinical practice, with the only problem being non-compliance with the prescribed footwear owing to poor socio-economic circumstances or personal preference.

The diabetic foot programme encompasses screening, examination, diagnostic tests, footwear recommendation, referrals, follow-ups and patient education. Diabetic foot education is an essential tool in diabetic foot programmes. ${ }^{51}$ Unfortunately, a considerable number of T2DM patients were not offered adequate self-care foot education, despite the presence of threatening risk factors for lower limb complications. The overall score for previous foot education in our study was poor, which was similar to the result obtained from a study conducted in a PHC setting in
Nigeria. ${ }^{21}$ Applied structured educational interventions on diabetic foot education are highly effective in improving knowledge and practices of T2DM patients about DFC. $7,26,50$ The results of a randomised controlled study on foot care education with group or individual counselling demonstrated a significant increase in diabetic patients' self-efficacy in caring for their feet. Neither of the two training methods (group or individual) is superior to the other in preventing DFD. Both methods show a similar positive effect in preventing DFD. ${ }^{26}$ Group counselling could be a realistic intervention for the South African setting which is often plagued with limited resources. However, in two other studies, a greater improvement in knowledge and practices was shown with individual counselling than with group education, especially in people with long-duration DM as it was postulated that they had impaired cognition owing to their long-standing illness. ${ }^{50,51}$ Group sessions are costand time-effective, whilst individual sessions provide better interaction but require more human resources. ${ }^{26,50}$ A structured programme of regular group education and feedback can easily be implemented in public sector settings with minimal use of resources. Peer education is another form of intervention that can easily be implemented at PHC or hospital level, and will improve awareness, attitude and practices of people with T2DM and hopefully improve clinical outcomes.

Men had an overall higher score for attitudes and practice, with a significant difference shown in the attitude score. Some studies found that men demonstrated better abilities than women with, however, some exceptions for women regarding certain specific self-care tasks. ${ }^{57}$ The positive relationship between education level and previous foot care education means that better educated individuals are more likely to demonstrate high scores for previous foot care education as they might be able to access information from various sources such as the internet or a library.

In the present study, we were able to identify participants with at-risk feet. However, we could not determine whether this was related to poor previous foot education of the participants.

\section{Conclusion and recommendations}

DFD causes deterioration in quality of life and affects the quality of care for diabetic patients. It poses a serious medical, social and economic challenge for the healthcare system. Poor knowledge combined with poor self-care practices compromises holistic patient care. The cost of managing DFD encompasses the care of foot ulcers, peripheral vascular diseases, peripheral neuropathy, foot infections and deformities. Many of these foot problems could be reduced if primary and secondary prevention were prioritised in routine clinical care. The patient with T2DM plays a crucial role in preventing foot disease. However, the healthcare system should empower diabetic patients with knowledge, skills and own foot care practices. 
The level of awareness of DFD was found to be suboptimal in our study. Furthermore, the clinical management of DFD was incidentally found to be poor. Better screening using a simple tool and a secondary prevention programme, as well as patient education, should be provided at chronic outpatients departments of the study's research site to minimise the burden of DFD. Prevention, however, requires adequate awareness of the problem. The study results highlighted areas in which preventative efforts to improve knowledge, attitudes and practices could be made. Effective strategies must focus on an aggressive approach to risk factor modifications, footwear inspection and advice, identification of at-risk feet, and diabetic foot care education. Ensuring that patients adhere to non-pharmacological and pharmacological measures is also crucial in ensuring success. An integrated patientcentered approach has been shown to provide adequate incentive to ensure patient adherence management plans. ${ }^{58}$

Specific recommendations to improve the quality of life of T2DM patients attending outpatient clinics include:

- introduction of regular screening for DFD when counselling T2DM patients

- providing group counselling on DFC regularly, using a diabetic educator in resource-limited settings and individual counselling in other settings

- facilitating peer support groups at health facilities so that patients can share knowledge of DFD and DFC

- collaborating with other healthcare providers such as podiatrists to provide comprehensive DFC

- establishing dedicated foot clinics

- empowering patients to request a foot examination yearly from their healthcare provider and that the findings be documented in clinical notes

- regularly evaluate the quality of life of patients with DFD and the impact on daily living activities

- implementing regular clinical audits to ensure standards of care for diabetic patients

- scheduled follow-ups and appropriate referrals

- assessing and grading those diabetic patients with at-risk feet, and active management of DFD features to reduce further incidence of DFD

- appropriate footwear recommendations, taking account of patients' socio-economic circumstances.

\section{Acknowledgements}

I thank first and foremost God Almighty; without Him none of this work would have been possible. A special thank you goes to the love of my heart for supporting me throughout this research. A cheerful thank you goes to Dr Andrew Ross for his input in this project. I also cannot forget to thank my parents, my dear family and friends for their prayers and love toward me.

\section{Competing interests}

The authors declare that they have no financial or personal relationships which may have inappropriately influenced them in writing this article.

\section{Authors' contributions}

T.T.G. was involved in conceptualising the study, data collection, data analysis, the report and writing of the manuscript. M.N. was involved in data verification and reviewing the manuscript.

\section{References}

1. Diabetes. World Health Organization Media Centre; 2015 [cited 2015 Jan 14]. 312. Available from: www.who.int/mediacentre/factsheets/fs312/en/

2. IDF Diabetes Atlas [serial online]. International Diabetes Federation; 2013; n.d. Available from: www.idf.org/diabetesatlas

3. Mbanya JC, Ramiaya K. Diabetes mellitus. In: Jamison DT, Feachem RG, Makgoba MW, et al. editors. Disease and mortality in sub-Saharan Africa. 2nd ed. Washington, DC: World Bank; 2006; p. 2254-2266.

4. Moodley LM, Rambiritch V. An assessment of the level of knowledge about diabetes mellitus among diabetic patients in a primary healthcare setting. $S$ Afr Fam Pract. 2007;49(10):16-16d.

5. McCulloch D, Robertson R. Risk factors for type 2 diabetes mellitus 2012. n.d.; UpToDate. Available from: www.uptodate.com/contents/risk-factors-for-type-2diabetes-mellitus

6. Leung P. Diabetic foot ulcers - A comprehensive review. Surgeon. 2007;5(4): 219-231. http://dx.doi.org/10.1016/S1479-666X(07)80007-2

7. Boulton A, Vileikyte L, Ragnarson-Tennvall G, Apelqvist J. The global burden of diabetic foot disease. Lancet. 2005;366:1719-1724. http://dx.doi.org/10.1016/ S0140-6736(05)67698-2

8. Diabetes mellitus and disorders of carbohydrate metabolism. In: Beers MH, Porter RS, Jones TV, Kaplan JL, Berwits M, editors. The Merck manual. 18th ed. New Jersey, USA: Merck Research Laboratories; 2006. p. 1274-1294.

9. Frykberg R, Armstrong D, Giurini J, et al. Diabetic foot disorders: A clinical practice guideline. J Foot Ankle Surg. 2000;39(5):S1-S66.

10. Yavuz D, Tuglular S, Ersoz H, Altun A, Archer A, Akalin A. Awareness of diabetic foot disease in a group of Turkish and English patients with type 2 Diabetes Mellitus: Assessment of the status and the efficacy of diabetic foot education programs. Turkish J Endocrinol Metab. 1999;2:65-70.

11. Dunbar GL, Hellenberg DA, Levitt NS. Diabetes mellitus and non-traumatic lower extremity amputations in four public sector hospitals in Cape Town, South Africa, during 2009 and 2010. S Afr Med J. 2015;105(12):1053-1056. http://dx.doi. org/10.7196/SAMJ.2015.v105i12.9276

12. Desalu O, Salawu F, Adekoya A, Busari O, Olokoba A. Diabetic foot care: Self reported knowledge and practice among patients attending three tertiary hospitals in Nigeria. Ghana Med J. 2011:45(2):60-65. http://dx.doi.org/10.4314/ gmj.v45i2.68930

13. McCulloch D. Patient information: Foot care in diabetes mellitus; 2013; n.d. Available from: www.uptodate.com

14. Roaeid R, Kadiki O. Prevalence of long-term complications among type 2 diabetic patients in Benghazi, Libya. J Diabetol. 2011;3(5):1-8.

15. Ricco J, Phong LT, Schneider F, et al. The diabetic foot: A review. J Cardiovasc Surg (Torino). 2013;54(6):755-762.

16. García-Morales E, Lázaro-Martínez JL, Martínez-Hernández D, Aragón-Sánchez J, Beneit-Montesinos JV, González-Jurado MA. Impact of diabetic foot related complications on the health related quality of life (HRQol) of patients - A regiona study in Spain. Int J Low Extrem Wounds. 2011;10(1):6-11. http://dx.doi. org/10.1177/1534734611400257

17. Winkley K, Stahl D, Chalder T, Edmonds M, Ismail K. Quality of life in people with their first Diabetic foot ulcer: A prospective cohort study. J Am Podiatr Med Assoc. 1999(5):406-414. http://dx.doi.org/10.7547/0990406

18. Peters E, Lipsky B. Diagnosis and management of infection in the diabetic foot. Med Clin North Am. 2013;97(5):911-946. http://dx.doi.org/10.1016/j. mcna.2013.04.005

19. Dilek G, Tuglular S, Onder H, Altun A, Archer A, Akalin S. Awareness of diabetic foot disease in a group of Turkish and English patients with type 2 diabetes mellitus: Assessment of the status and the efficacy of diabetic foot education programs. Turkish J Endocrinol Metab. 1999;2:65-70.

20. Pinto A, Tuttolomondo A, DiRaimondo D, et al. Cardiovascular risk profile and morbidity in subjects affected by type 2 diabetes mellitus with and without diabetic foot. Metabolism. 2008;57:672-682. http://dx.doi.org/10.1016/j. metabol.2008.01.004

21. Ekore R, Ajayi I, Arije A, Ekore J. Knowledge of and attitude to foot care amongst type 2 diabetes patients attending a university-based primary care clinic in Nigeria. Afr J Prim Health Care Fam Med. 2010;2(10):1-3. http://dx.doi. org/10.4102/phcfm.v2i1.175

22. Boulton A, Jude E. Friends of the oppressed foot? Diabetes Care. 2001;24(4) 615-616. http://dx.doi.org/10.2337/diacare.24.4.615

23. Nyamu P, Otieno C, Amayo E, Mcligeyo S. Risk factors and prevalence of diabetic foot ulcers at Kenyatta National Hospital, Nairobi. East Afr Med J. 2003;80(1): 36-43.

24. Leslie K, Nkombua L. Evaluation of general practitioners' routine assessment of patients with diabetes in Tshwane, South Africa. S Afr Fam Pract. 2012;54(1): 68-71. http://dx.doi.org/10.1080/20786204.2012.10874178 
25. Lincoln N, Radford K, Game F, Jeffcoate W. Education for secondary prevention of foot ulcers in people with diabetes: A randomised controlled trial. Diabetologia. 2008;51(11):1954-1961. http://dx.doi.org/10.1007/s00125-008-1110-0

26. Seyyedrasooli A, Parvan K, Valizadeh L, Rahmani A, Zare M, Izadi T. Self-efficacy in foot care and effect of training: A single-blinded randomized controlled clinical trial. Int J Community Based Midwifery. 2015;3(2):141-149.

27. Chellan G, Srikumar S, Varma AK, et al. Foot care practice - The key to prevent diabetic foot ulcers in India. Foot. 2012;22(4):298-302. http://dx.doi. org/10.1016/j.foot.2012.08.007

28. Hasnain S, Sheik $\mathrm{NH}$. Knowledge and practices regarding foot care in diabetic patients visiting diabetic clinic in Jinnah Hospital, Lahore. J Pak Med Assoc. 2009;59(10):687-690.

29. Upadhyay DK, Palaian S, Shankar PR. Knowledge, attitude and practice about diabetes among diabetes patients in Western Nepal. RMJ. 2008;33(1):8-11.

30. The pampered foot. Diabetes foot care questionnaire. 2011; n.d. Available from www.thepamperedfoot.com

31. Dixit S, Maiya A, Khetrapal H, Agrawal B, Vidyasagar S, Umakanth S. A questionnaire based survey on awareness of diabetic foot care in India population with diabetes: A cross-sectional multicentre study. India J Med Sci. 2011;65(10):411-423. http:// dx.doi.org/10.4103/0019-5359.109224

32. Babwah F, Baksh S, Blake L, et al. The role of gender in compliance and attendance at an outpatient clinic for type 2 diabetes mellitus in Trinidad. Pan Am J Public Health. 2006;19(2):79-84. http://dx.doi.org/10.1590/\$1020-49892006000200002

33. Masango-Makgobela A, Govender I, Ndimande J. Reasons patients leave their nearest healthcare service to attend Karen Park Clinic, Pretoria North. Afr J Prim Health Care Fam Med. 2013;5(1):1-5. http://dx.doi.org/10.4102/phcfm.v5i1.559

34. Gale E, Gillespie K. Diabetes and gender. Diabetologia. 2001;44(1):3-15. http:// dx.doi.org/10.1007/s001250051573

35. WHO. Differences by sex in the prevalence of diabetes mellitus, impaired fasting glycaemia and impaired glucose tolerance in sub-Saharan Africa: A systematic review and meta-analysis. Japan2013 [25 March 2013]. Bulletin of the World Health Organization.

36. Tobias $D$, Jackson $C$, O'Reilly E, et al. Body-mass index and mortality among adults with incident type 2 diabetes. N Engl J Med. 2014;370:233-244. http://dx.doi. org/10.1056/NEJMoa1304501

37. Fox C, Golden S, Bray G, et al. Update on prevention of cardiovascular disease in adults with type 2 diabetes mellitus in light of recent evidence: A Scientific statement from the American Heart Association and the American Diabetes Association. from the American Heart Association and the American Diabetes Association.

38. Aune D, Norat T, Leitzmann M, Tonstad S, Vatten L. Physical activity and the risk of type 2 diabetes: A systematic review and dose-response meta-analysis. Eu J Epidemiol. 2015;30(7):529-542. http://dx.doi.org/10.1007/s10654-015-0056-z

39. Dutra L, Williams D, Kawachi I, Okechukwu C. Racial and non-racial discrimination and smoking status among South African adults 10 years after apartheid. BMJ. 2014;23:85-86. http://dx.doi.org/10.1136/tobaccocontrol-2013-051478

40. Saloojee Y. Chapter 5: Tobacco control in South Africa. Cape Town, South Africa: Chronic Diseases of Lifestyle in South Africa: 1995-2005, South African Medical Council, 2006

41. Chapter 2: Recent trends in smoking prevalence in South Africa. The Economics of Tobacco Control in South Africa; Health and Medical Publishing /group; 2003.
42. Association AD. Peripheral arterial disease in people with diabetes. J Am Podiatr Med Assoc. 2005;95(3):309-319. http://dx.doi.org/10.7547/0950309

43. Althouse A, Abbott J, Forker A, et al. Risk factors for incident peripheral arterial disease in type 2 diabetes: Results from the bypass angioplasty revascularization investigation in type 2 diabetes (BARI 2D) trial. Diabetes Care. 2014;37(5): 1346-1352. http://dx.doi.org/10.2337/dc13-2303

44. Singh N, Armstrong D, Lipsky B. Preventing foot ulcers in patients with diabetes. Am Med Assoc. 2005;293(2):217-228. http://dx.doi.org/10.1001/jama. 293.2.217

45. Grol R, Wensing M. What drives change? Barriers to and incentives for achieving evidence-based practice. Med J Aust. 2004;180:S57-S60.

46. Ku GMV, Kegels G. Knowledge, attitudes and perceptions of people with type 2 diabetes as related to self-management practices: Results of a cross-sectional study conducted in Luzon, Philippines. Chronic Illn. 2014;11:93-107. http://dx. doi.org/10.1177/1742395314538291

47. Haire-Joshu D, Glasgow R, Tibbs T. Smoking and diabetes. Diabetes Care. 1999;22(11):1887-1898. http://dx.doi.org/10.2337/diacare.22.11.1887

48. Al-Rubeaan K, Derwish MA, Ouizi S, et al. Diabetic foot complications and their risk factors from a large retrospective cohort study. PLoS One. 2015;10(5):1-17. http://dx.doi.org/10.1371/journal.pone.0124446

49. Levitt N, Bradshaw D, Zwarenstein M, Bawa A, Maphumolo S. Audit of public sector primary diabetes care in Cape Town, South Africa: High prevalence of
complications, uncontrolled hyperglycaemia, and hypertension. Diabet Med. 1997:14(12):1073-1077. http://dx.doi.org/10.1002/(sici)1096-9136(199712)14:12 $<1073$ ::aid-dia498>3.3.co;2-0

50. Vatankhah N, Khamseh $M$, Noudeh $Y$, Aghili R, Baradaran H, Haeri N. The effectiveness of foot care education on people with type 2 diabetes in Tehran, Iran. Prim Care Diabetes Eur. 2009;3:73-79. http://dx.doi.org/10.1016/j.pcd. 2009.05.003

51. Gondal M, Bano U, Moin S, Afridi Z, Masood R, Ahmed A. Evaluation of knowledge and practices of foot care in patients with chronic type 2 diabetes mellitus. JPMI. 2007;21(2):104-108

52. SEMDSA. Diabetes foot care guidelines for primary healthcare professionals Society of Endocrinology, Metabolism and Diabetes of South Africa; Society of Endocrinology, Metabolism and Diabetes of South Africa, 2012.

53. McInnes A, Jeffcoate W, Vileikyte L, et al. Foot care education in patients with diabetes at low risk of complications: A consensus statement. Diabetic Med. 2010;28:162-167. http://dx.doi.org/10.1111/j.1464-5491.2010.03206.x

54. Green B, Zoepke A. Diabetes and diabetic foot ulcer: An often hidden problem. S Afr Fam Pract. 2013;55(6):515-518. http://dx.doi.org/10.1080/20786204.2013. S Afr Fam P
10874409

55. Clarke A. Foot complications in diabetes are serious and costly. Afr J Online. 2010;28(4):181-185.

56. Clarke $\mathrm{E}$. The role of the podiatrist in managing the diabetic foot ulcer. Wound Healing Southern Africa. 2008;1(1):40-42.

57. Halpern D. Sex differences in cognitive abilities. New York: Psychology press; 2012.

58. Ribu L, Hanestad B, Moum T, Birkeland K, Rustoen T. Health-related quality of life among patients with diabetes and foot ulcers: Association with demographic and clinical characteristics. J Diabetes Complicat. 2007;21:227-236. http://dx.doi. org/10.1016/j.jdiacomp.2007.02.001 